\title{
An Improved Fault Location Method for Distribution Networks Exploiting Emerging LV Smart Meters
}

\author{
Abouzar Estebsari, Enrico Pons, Ettore Bompard \\ Department of Energy \\ Politecnico di Torino \\ Turin, Italy, 10129
}

\author{
Alireza Bahmanyar, Sadegh Jamali \\ Department of Electrical Engineering \\ Iran University of Science and Technology \\ Tehran, Iran, 1684613114
}

\begin{abstract}
In the last years, the electrical distribution systems are undergoing one of their largest transitions in their long history towards smart grids. One of the key requirements and the first step in the path of smart grid is developing and deploying smart metering systems in distribution networks. In this regard, several projects co-funded by the European Commission (EC) have been carried out. FLEXMETER is one of the ongoing EU Horizon 2020 projects aiming at the development and demonstration of a flexible smart metering architecture. In this paper, first the different available measurements in the FLEXMETER project are introduced. Then different fault location methods are compared qualitatively and quantitatively to find the most appropriate one based on the FLEXMETER infrastructure. Finally a combined method as a hybrid solution is proposed to overcome the drawbacks of the previously proposed ones, while keeping their advantages.
\end{abstract}

Keywords-Distribution networks; Fault location; Outage location; Smart grid; Smart meters.

\section{INTRODUCTION}

In the last years distribution networks are facing great changes and are moving towards the smart grid concept. One of the key aspects of smart grids is the presence of an advanced metering infrastructure, providing new services to the different actors (final users, prosumers, distribution system operator DSO, retailers, etc.).

In the FLEXMETER project, a H2020 research project cofounded by the European Commission, a flexible smart metering architecture for multiple energy vectors is being deployed and will be tested in two demonstrators, Torino and Malmö [1]. The utilities involved in FLEXMETER will be electricity, gas, heat and water.

For what concerns electricity, FLEXMETER is deploying different prototypal and off-the-shelf meters [2] to be installed at the final users' premises and in the MV/LV substations at the LV feeders head. The FLEXMETER infrastructure, based on the new deployed meters, will allow for different services for the users, for the DSO, for the retailers, etc. One of the applications, for the DSO, will be outage detection, outage location, and fault location.

Distribution networks are usually dispersed over vast geographical areas and may experience different types of faults arising from different sources such as adverse weather conditions, road works and equipment failure [3]. Primary distribution network faults affect a large number of customers and are one of the major concerns of DSOs. Better management of distribution network faults can reduce outage times, improve the quality of supply and enhance system reliability [4].

In traditional distribution networks, after the occurrence of an outage caused by a specific fault in MV, DSOs usually use techniques such as a sequence of switching operations on remotely controlled or manually operated switches to make a primary estimation of the faulted area. For LV faults, the DSO normally uses customer calls. Then, they send the maintenance crew to patrol the area and find the fault evidences. The crew isolates the faulty section and restores the customers connected to the healthy sections of the feeder. The whole process may take from tens of minutes to hours.

The FLEXMETER infrastructure provides the possibility of better fault management and fault location methods. In case of outage, all the meters in the outage area detect the absence of voltage and send a "last gasp" signal to the cloud system. The last gasp message should contain at least the error code, the ID of the meter and a time stamp. In this case it is possible to find the LV outage area. The overall procedure is similar to the traditional methods using trouble calls; however, the DSO does not need to wait for sufficient number of customer calls to find the outage area. In addition to outage location, thanks to the measurements at HV/MV substations, it is possible to design an algorithm to identify the fault location on the primary MV lines. For this purpose the meters in the HV/MV substation feeding the fault send the current and voltage waveforms or phasors immediately after the fault detection. In addition to HV/MV substation measurements and smart meters "last gasp" signal, the measured voltages and currents at some of the secondary $\mathrm{MV} / \mathrm{LV}$ substations are also available in the central cloud. The amount of data to be sent is quite small and there are no stringent latency requirements. The main issue is that the meters and communication network should work also in a power outage condition.

Considering the different proposed fault location methods for distribution networks [5]-[15], selection of an appropriate one for a certain system is a task that requires special investigations. Each method has its advantages and disadvantages and requirements. Therefore, a method which is applied on a certain system would be impractical for another one. In this paper we compare different fault location methods to find the most appropriate one based on the FLEXMETER infrastructure. Different classes of distribution fault location methods are first compared qualitatively to select the most appropriate one based on their requirements, advantages and disadvantages. Two methods are then selected and compared 
quantitatively to investigate their limitations and advantages. Finally a combined method is proposed to overcome the drawbacks of the previously proposed methods, while keeping their advantages. The proposed method matches the FLEXMETER infrastructure and its requirements, and exploits the new installation of smart meters in secondary substations.

\section{Distribution FAUlt Location Methods: Qualitative COMPARISON}

Distribution networks are usually operated radially and may have several laterals and loads. Moreover, because of their progressive development by time, these networks usually have nonhomogeneous lines. Following issues are some problems of distribution networks fault location:

- Geographic dispersion of distribution networks and limited number of measurements;

- The status of switching and protection devices are seldom available;

- Nonhomogeneous overhead lines and cables;

- Presence of branches, laterals and single-phase and three-phase loads with unknown values;

- Dynamic configuration of the network;

- The effect of fault arc resistance which is considerable;

- Multiple fault location in distribution networks due to presence of several branches.

Therefore, considering the different nature of distribution networks, transmission fault location methods cannot be applied to them. There are a number of methods already proposed for fault location in electrical distribution systems. The methods can be classified to impedance-based methods [5]- [7], travelling waves-based methods [8], neural networkbased methods [9] and methods using sparse voltage measurements [10]-[15].

The impedance-based fault location methods are the most commonly used for transmission and distribution networks. These methods are based on the calculation of the impedance to the fault from the substation point of view and on the calculation of fault distance by solving the equations which describe fault steady state condition. The requirements of these methods include the fundamental-frequency voltage and current measurements available at the substation and data such as network topology, line impedances and distribution loads. The impedance-based algorithms are the most practical class of distribution fault location algorithms in terms of their requirements which are usually available in any distribution system. However, because of the branched nature of distribution networks, these algorithms usually report multiple locations for a single fault having the same impedance to the point of measurement.

Methods based on fault generated travelling waves have shown to have very accurate results for transmission lines. The distance to fault is calculated based on the travel time from the fault to line terminals calculated by investigating the changes in the recorded signals or by investigation of the frequency content of recorded transients. Despite their accurate results for single transmission and distribution lines, travelling wavesbased methods require measurements with very high frequency sampling rate which are expensive for distribution level. Moreover, in distribution networks with several branches and tapped loads which reflect travelling waves, accurate analysis of fault generated signals would be a demanding task requiring mathematical tools such as wavelet transform and neural networks. Thus, these methods are more appropriate for comparatively longer transmission line equipped with better measurements.

Neural network-based methods are alternatives with less online computation times. These methods have two main phases. In the offline phase, they use a relatively huge set of input-output patterns to train a neural network. The input usually includes the distribution network measurements or fault evidences and the output is the distance to fault. In the online phase, the trained neural networks use the gathered inputs to locate the fault. Despite their generalization capability and low online estimation time, the main problem of the neural network-based methods is the huge amount of simulated or real data they need for training. Moreover, the training have to be repeated following to any change in system such as reconfiguration.

TABLE I QUALITATIVE COMPARISON OF DIFFERENT FAULT LOCATION ALGORITHMS

\begin{tabular}{|c|c|c|c|c|}
\hline methods & Required data & Required measurements & $\begin{array}{c}\text { Requiring a communication } \\
\text { network }\end{array}$ & Disadvantages \\
\hline $\begin{array}{l}\text { Impedance-based } \\
\text { methods }\end{array}$ & $\begin{array}{l}\text { Line data } \\
\text { Load data } \\
\text { Network topology }\end{array}$ & $\begin{array}{lll}\begin{array}{l}\text { Substation } \\
\text { current }\end{array} & \text { voltage } & \text { and } \\
\end{array}$ & $x$ & Multiple estimation \\
\hline $\begin{array}{c}\text { Travelling waves-based } \\
\text { methods }\end{array}$ & Network topology & $\begin{array}{l}\text { Measurements with very high } \\
\text { sampling rate }\end{array}$ & & $\begin{array}{l}\text { Requiring measurements } \\
\text { with very high sampling } \\
\text { rate }\end{array}$ \\
\hline $\begin{array}{c}\text { Neural network-based } \\
\text { methods }\end{array}$ & $\begin{array}{l}\text { Line data } \\
\text { Load data } \\
\text { Network topology }\end{array}$ & Depends on the model & $\sqrt{ }$ & $\begin{array}{l}\text { Requiring retraining with } \\
\text { any change in network }\end{array}$ \\
\hline $\begin{array}{c}\text { Sparse voltage } \\
\text { measurements-based } \\
\text { methods }\end{array}$ & $\begin{array}{l}\text { Line data } \\
\text { Load data } \\
\text { Network topology }\end{array}$ & $\begin{array}{l}\text { Substation voltage and } \\
\text { current } \\
\text { Sparse voltage measurements }\end{array}$ & & $\begin{array}{l}\text { Not applicable to traditional } \\
\text { networks }\end{array}$ \\
\hline
\end{tabular}


Inspired by the recent developments in distribution networks infrastructures in terms of measuring and communication technologies, some fault location methods have been recently proposed, which are trying to take advantage of these new equipment to overcome the problems mentioned for pervious methods. These methods consider the fault at each node and calculate the change in three phase voltages at all nodes having voltage measurements. Then, comparing the measured and calculated voltages, they identify the nearest node to fault location. As mentioned previously, in traditional distribution systems, measurements are only available at primary substations. Therefore, these methods require new installations to be applied on traditional distribution networks; however, they are a good option for modern networks.

Table I presents a qualitative comparison of different fault location methods in terms of their requirements and disadvantages. Based on this table and the pervious discussions about the FLEXMETER project and the available measurements, Impedance-based methods and methods based on sparse voltage measurements are selected as the most practical class of methods for the project. In the next sections, the performance of these methods is evaluated through simulation studies to find the most appropriate one.

\section{Distribution FAULT LOCATION METHODS: QUANTITATIVE COMPARISON}

In this part, the impedance-based method proposed in [6] and the method proposed in [10] which is based on the sparse measured voltages are compared through simulation studies. First, the 134 node distribution network shown in Fig. 1 is simulated in ATP-EMTP. Then, the generated voltage and current waveforms for each considered fault scenario are transferred to MATLAB in which the fault location algorithms are tested. Several fault cases are simulated and the obtained results for some of them are reported. Because of the similarity of results for different types of faults, only the results for single-line to ground faults are presented.

The impedance-based fault location algorithm uses the fundamental-frequency voltage and current measured at the primary substation to find the fault location. They start from the first line section and solve fault equations to make an estimation of distance to the fault. In this step, if the calculated fault distance is beyond the line section length, it means that the fault is not in that section and the process should be repeated for the next section with the updated voltage and current values at the section head. Continuing this procedure, the impedance-based algorithms search all line sections and find all possible fault locations. Table II shows the different

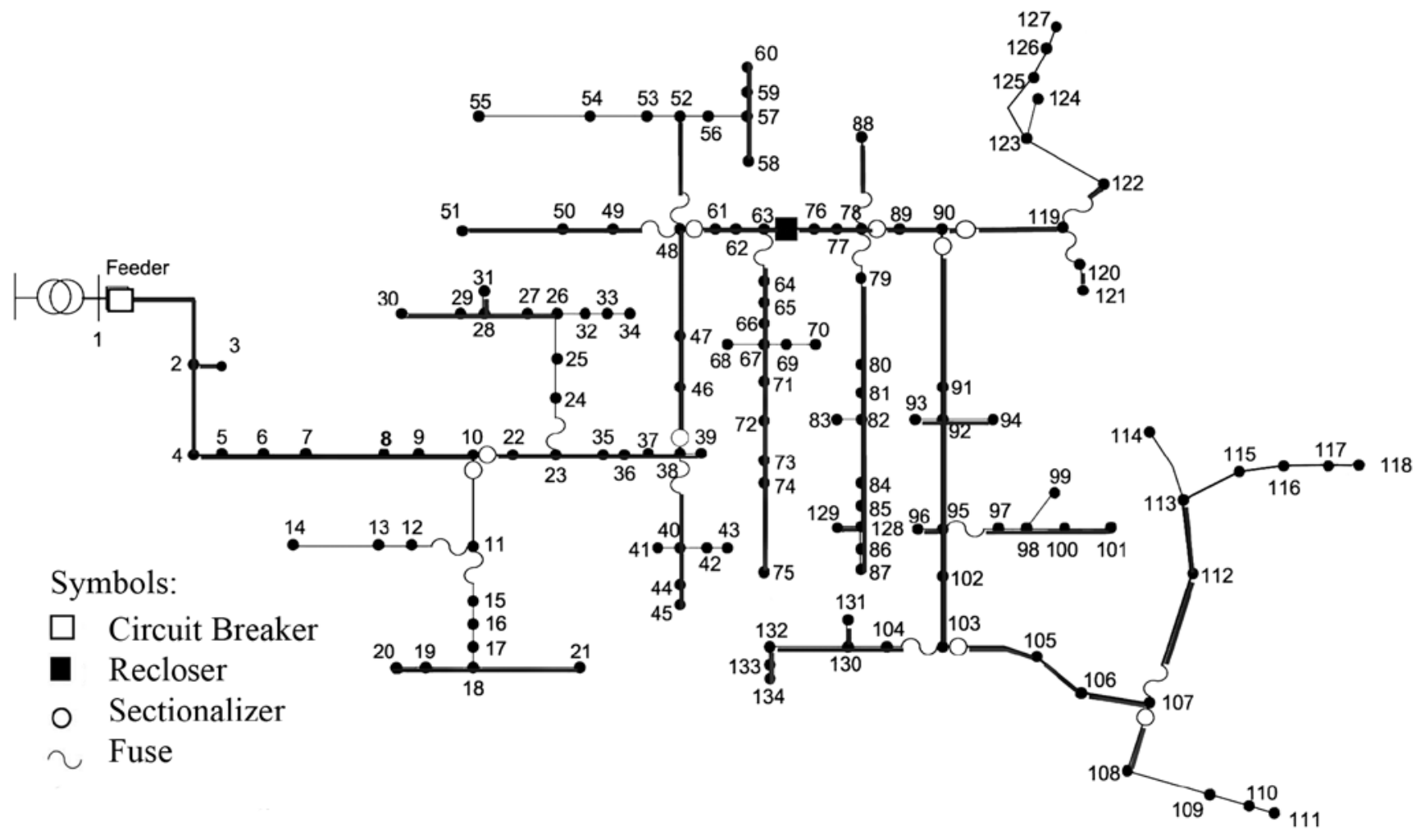

Fig. 1. Single line diagram of 134 node distribution feeder [13] 
TABLE II FAULT LOCATION RESULTS FOR THE IMPEDANCE-BASED ALGORITHM PROPOSED IN [6]

\begin{tabular}{|c|c|c|c|c|}
\hline $\begin{array}{c}\text { Fault } \\
\text { scenario }\end{array}$ & $\begin{array}{l}\text { Distance } \\
\text { to fault } \\
\text { (m) }\end{array}$ & $\begin{array}{l}\text { Reported } \\
\text { locations }\end{array}$ & $\begin{array}{l}\text { Reported } \\
\text { distances }\end{array}$ & $\begin{array}{c}\text { Estimated } \\
\text { fault } \\
\text { resistance } \\
(\Omega)\end{array}$ \\
\hline $\begin{array}{c}\text { Fault at } \\
\text { line } \\
2-4 \text { with } \\
R_{\mathrm{F}}=2 \Omega\end{array}$ & 50 & $\begin{array}{l}2-4 \\
2-3\end{array}$ & $\begin{array}{l}44.2 \\
45\end{array}$ & $\begin{array}{l}2.82 \\
2.94\end{array}$ \\
\hline $\begin{array}{c}\text { Fault at } \\
\text { line } \\
38-40 \text { with } \\
R_{F}=5 \Omega\end{array}$ & 50 & $\begin{array}{l}46-38 \\
27-26 \\
38-40 \\
38-39 \\
33-34 \\
21-18 \\
20-19 \\
13-14\end{array}$ & $\begin{array}{l}40.48 \\
40.46 \\
41.88 \\
42 \\
15.2 \\
41.48 \\
1.48 \\
51\end{array}$ & $\begin{array}{l}4.82 \\
4.99 \\
4.99 \\
4.73 \\
4.74 \\
4.72 \\
4.98 \\
4.88\end{array}$ \\
\hline $\begin{array}{c}\text { Fault at } \\
\text { line } \\
76-63 \text { with } \\
R_{\mathrm{F}}=5 \Omega\end{array}$ & 10 & $\begin{array}{l}76-63 \\
64-63 \\
52-56 \\
52-53 \\
50-51\end{array}$ & $\begin{array}{l}1.52 \\
1.48 \\
4 \\
4 \\
34.4\end{array}$ & $\begin{array}{l}4.99 \\
4.97 \\
4.77 \\
4.78 \\
4.95\end{array}$ \\
\hline $\begin{array}{c}\text { Fault at } \\
\text { line } \\
105-106 \\
\text { with } \\
R_{\mathrm{F}}=10 \Omega\end{array}$ & 105 & $105-106$ & 199.8 & 9.97 \\
\hline
\end{tabular}

reported location for four different fault scenarios. As can be seen in this table, the impedance-based method accurately locates the fault; however, it reports multiple locations for a single fault.

The fault location method proposed in [10] considers the fault as a special load temporarily connected to the faulted node. It assumes the fault at each node, one at a time, performs a power flow updating the fault current at each iteration and investigates the mismatches between the calculated duringfault voltage sags and measured during-fault voltage sags. The proposed methods calculate a mismatch index for each node and introduces the node with the maximum value of index (i.e. minimum mismatch) as the nearest node to the fault.

Supposing that four voltage measurements with communication capabilities are installed at nodes $20,81,115$ and 125, Fig. 2 shows the index values for four considered fault scenarios. As shown in this figure, in all cases, the method proposed in [10] finds the nearest node to fault location. However, in some cases the index values are very close to each other. For example for a fault at line 63-76, all the nodes between nodes 63 and 76 have almost the same value of the index. In such a situation, even small measurement errors would result in wrong results.

\section{The Proposed ENHANCED Method}

Based on the presented results and discussions, Impedancebased methods have accurate fault location results, but they report multiple locations for a single fault. On the other hand, the methods based on sparse voltage measurements do not have the multiple estimation problems, but they are sensitive to measurement errors and their accuracy is limited to the nearest node to fault location. Is this section a combined method is proposed to overcome the drawbacks of the previously proposed methods, while keeping their advantages.

As can be seen in Table II, the impedance-based method proposed in [6] calculates a fault resistance for each reported fault location. Therefore, the proposed combined method first performs an impedance-based algorithm to find the possible locations for fault and the related fault impedance values. It then applies the fault at each point reported by the impedancebased method with the calculated fault resistance and investigates the similarity between the calculated voltage sags and measured voltage sags to find the correct solution.

In FLEXMETER project the meters in the $\mathrm{MV} / \mathrm{LV}$ substation send the during-fault current and voltage waveforms or phasors immediately after the outage detection. The proposed methods use the MV side voltages, which can be calculated using the available MV/LV substation measurements. As described in Section II and Table I, methods based on sparse voltage measurements, because of their measurement requirements, are not applicable to traditional networks. The proposed is designed to work with only one measurement device in addition to substation voltage and
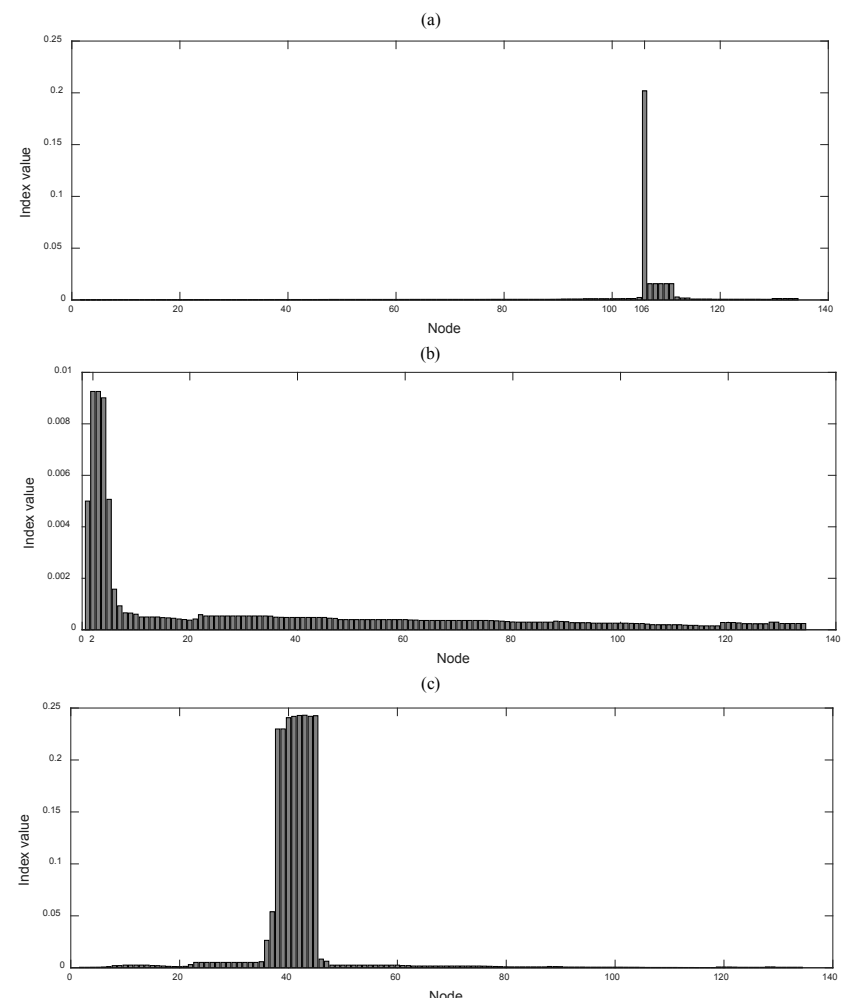

(d)

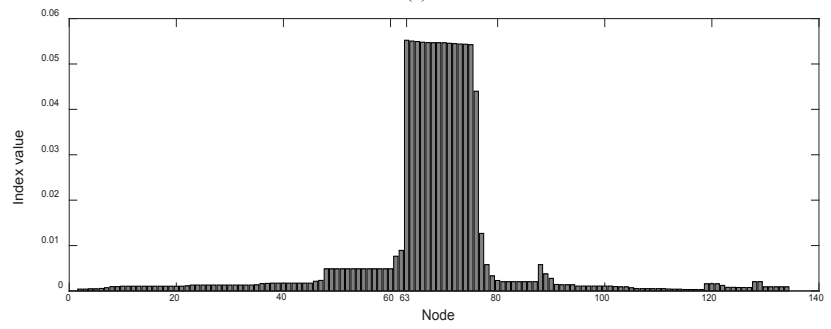

Fig. 2. Fault location results for sparse voltage measurements-based method proposed in [10] 
current measurements. Therefore, it requires very little investment to be implemented on any traditional network. However, increasing the number of measurements can improve its reliability. Fig. 2 shows the flowchart of the proposed algorithm. For each possible fault location, the method applies the fault with the estimated fault resistance and calculates the following index. Finally it selects the fault location with the maximum value of index (minimum difference between the calculated and measured voltage sags) as the correct solution.

$$
\eta_{i}=\frac{1}{\Delta V^{m}-\Delta V_{i}^{c}}
$$

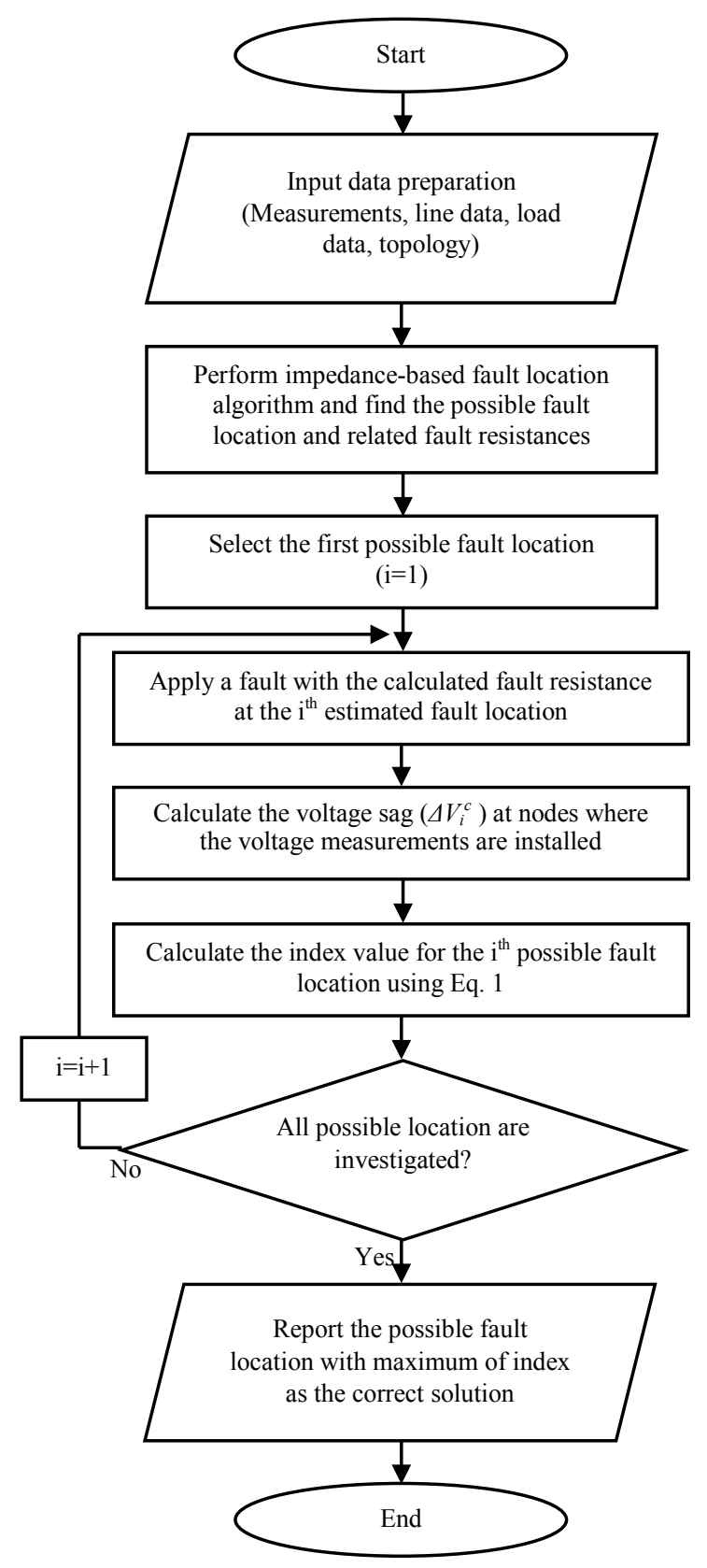

Fig. 3. Flowchart of the proposed combined method where $\Delta V^{m}$ is the measured voltage sag and $\Delta V_{i}^{c}$ in the calculated voltage sag for $i^{\text {th }}$ possible fault location at the node where measurement device is installed.

To test the performance of the proposed method, consider a fault at line $38-40,50 \mathrm{~m}$ from node 40 . In the first phase, the impedance-based algorithm reports 8 possible location with related fault resistances as previously shown in Table II. In the second phase, supposing that one voltage measurement device is installed at node 63, the fault is applied at each location with the calculated resistance and the index value is calculated for each of them. Fig. 3 shows the calculated index values for all reported locations.

As can be seen in this figure, the fault location at line $38-40$ has the largest value of index and is selected as fault location. The calculated distance is about 42 meters from node 38 and the fault location error is just 8 meters implying the accuracy of the proposed method.

For a fault at line 76-63,10m from node 63, the impedancebased algorithm reports 5 possible locations with related fault resistances. Fig. 4 shows the calculated index values for all reported locations. It can be seen that also in this case the proposed algorithm successfully finds the correct faulted line. The location of the fault is estimated at about 2 meters from node 63 having less than 8 meters estimation error.

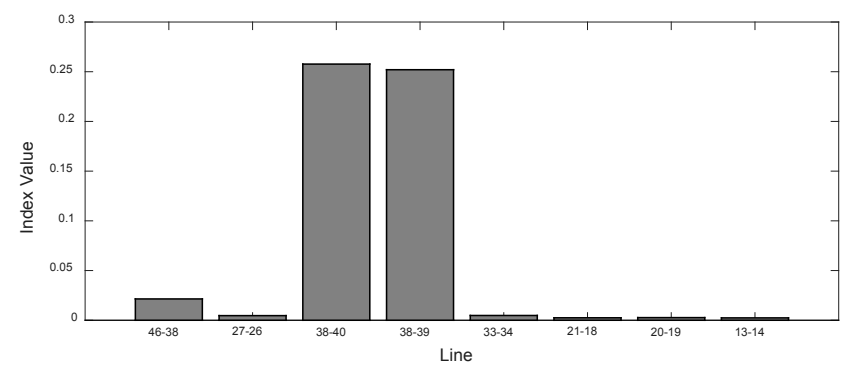

Fig. 4. Fault location results of the proposed method for fault at line $38-40$

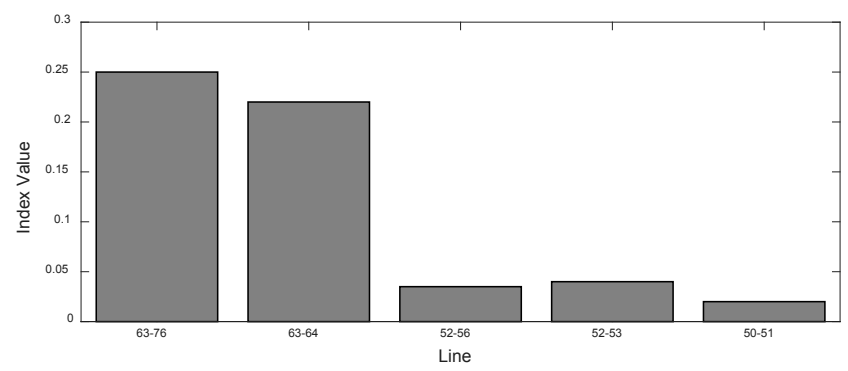

Fig. 5. Fault location results of the proposed method for fault at line 76-63

Several other cases are also considered and Table III presents some of the obtained results for the proposed method and the method proposed in [10]. As can be seen in this table, almost in all cases the proposed method provides more accurate results. Moreover, compared to the impedance-based method proposed in [6], it always reports one location for each fault scenario. Therefore, the proposed method not only overcome the drawbacks of the previously proposed methods, but also keeps their advantages. 
TABLE III FAULT LOCATION RESULTS FOR THE PROPOSED METHOD AND THE METHOD PROPOSED IN [6]

\begin{tabular}{|c|c|c|c|}
\hline Fault scenario & $\mathbf{R}_{\mathbf{F}}$ & $\begin{array}{l}\text { Proposed } \\
\text { method }\end{array}$ & $\begin{array}{c}\text { Voltage sag- } \\
\text { based } \\
\text { method }\end{array}$ \\
\hline \multirow{2}{*}{$\begin{array}{c}\text { Fault at line } 54-55 \\
39 \mathrm{~m} \text { from } 54\end{array}$} & $5 \Omega$ & 1.37 & 279 \\
\hline & $20 \Omega$ & 20.23 & 229 \\
\hline \multirow{2}{*}{$\begin{array}{c}\text { Fault at line } 74-75 \\
55 \mathrm{~m} \text { from } 74\end{array}$} & $5 \Omega$ & 1.32 & 55 \\
\hline & $20 \Omega$ & 19.85 & 55 \\
\hline \multirow{2}{*}{$\begin{array}{c}\text { Fault at line } 90-119 \\
44 m \text { from } 90\end{array}$} & $5 \Omega$ & 1.37 & 44 \\
\hline & $20 \Omega$ & 20.29 & 44 \\
\hline \multirow{2}{*}{$\begin{array}{c}\text { Fault at line 109-110 } \\
15 \mathrm{~m} \text { from } 109\end{array}$} & $5 \Omega$ & 1.81 & 15 \\
\hline & $20 \Omega$ & 32 & 15 \\
\hline
\end{tabular}

\section{CONCLUSION}

In this paper we introduced the available measurements in one of the ongoing EU Horizon 2020 projects (FLEXMETER) and tried to compare different fault location methods to find the most accurate and appropriate one which can exploit the new measurements and the cloud-based communication system proposed in this project. Different classes of distribution fault location methods are first compared qualitatively to select the most appropriate one based on their requirements, advantages and disadvantages. Two methods are then selected and compared quantitatively. The simulation results show that both methods have acceptable results but they have shortcomings. Therefore, a combined method is proposed to overcome the drawbacks of the previously proposed methods, while keeping their advantages. Based on the presented simulation results for different fault scenarios, compared to the methods proposed in [6],[10], the proposed method always reports one location for each fault scenario and constantly provides accurate results. Therefore, the proposed method not only matches the FLEXMETER infrastructure but also satisfies its requirements.

\section{REFERENCES}

[1] E. Patti, E. Pons, D. Martellacci, F. B. Castagnetti, A. Acquaviva, and E. Macii, "multiFLEX: Flexible Multi-Utility, Multi-Service Smart Metering Architecture for Energy Vectors with Active Prosumers," in Proceedings of the 4th International Conference on Smart Cities and Green ICT Systems (SMARTGREENS), 2015.

[2] A. Bahmanyar, A. Estebsari, E. Pons, S. Jamali, E. Bompard, E. Patti, and A. Acquaviva, "Emerging Smart Meters in Electrical Distribution
Systems: Opportunities and Challenges," in 24th Iranian Conference on Electrical Engineering (ICEE), 2016, accepted for publication.

[3] E. Bompard, A. Estebsari, T. Huang, and G. Fulli, "A framework for analyzing cascading failure in large interconnected power systems: A post-contingency evolution simulator," International Journal of Electrical Power \& Energy Systems, vol. 81, pp. 12-21, 2016.

[4] T. Huang, S. Voronca, A. Purcarea, A. Estebsari, and E. F. Bompard, "Analysis of chain of events in major historic power outages," Advances in Electrical and Computer Engineering, vol. 14, pp. 63-70, 2014.

[5] R. Das, M. S. Sachdev, and T. S. Sidhu, "A fault locator for radial subtransmission and distribution lines," in IEEE Power Engineering Society Summer Meeting, Seattle, 2000, pp. 443-448 vol. 1.

[6] L. Seung-Jae, C. Myeon-Song, K. Sang-Hee, J. Bo-Gun, L. Duck-Su, A. Bok-Shin, et al., "An intelligent and efficient fault location and diagnosis scheme for radial distribution systems," IEEE Transactions on Power Delivery, vol. 19, pp. 524-532, 2004.

[7] S. Jamali and V. Talavat, "Accurate fault location method in distribution networks containing distributed generations," Iranian Journal of Electrical and Computer Engineering, vol. 10, pp. 27-33, 2011.

[8] A. Borghetti, M. Bosetti, C. A. Nucci, M. Paolone, and A. Abur, "Integrated use of time-frequency wavelet decompositions for fault location in distribution networks: theory and experimental validation," IEEE Transactions on Power Delivery, vol. 25, pp. 3139-3146, 2010.

[9] D. Thukaram, H. P. Khincha, and H. P. Vijaynarasimha, "Artificial neural network and support vector Machine approach for locating faults in radial distribution systems," IEEE Transactions on Power Delivery, vol. 20, pp. 710-721, 2005.

[10] R. A. F. Pereira, L. G. W. da Silva, M. Kezunovic, and J. R. S. Mantovani, "Improved fault location on distribution feeders based on matching during-fault voltage sags," IEEE Transactions on Power Delivery, vol. 24, pp. 852-862, 2009.

[11] S. Jamali, A. Bahmanyar and H. Borhani-Bahabadi, "A Fast and accurate fault location method for distribution networks with DG using genetic algorithms" Smart Grid Conference (SGC), Dec. 2015.

[12] S. Jamali, A. Bahmanyar, A new fault location method for distribution networks using sparse measurements, International Journal of Electrical Power \& Energy Systems, 81 (2016) 459-468.

[13] F. C. L. Trindade, W. Freitas, and J. C. M. Vieira, "Fault location in distribution systems based on smart feeder meters," IEEE Transactions on Power Delivery, vol. 29, pp. 251-260, 2014.

[14] M.Majidi, M.Etezadi-Amoli, and M.S.Fadali, "A novel method for single and simultaneous fault location in distribution networks," IEEE Transactions on Power System. Vol. 30, Issue 6, pp. 3368-3376, Nov. 2015.

[15] M.Majidi, A.Arabali, and M.Etezadi-Amoli, "Fault location in distribution networks by compressive sensing," IEEE Transactions on Power Delivery. Vol. 30, Issue 4, pp. 1761-1769, Aug. 2015. 